\title{
Patient satisfaction after breast cancer surgery
}

\author{
A prospective clinical trial
}

\author{
Carmen Leser (D) - Yen Y. Tan · Christian Singer · Robert Zeillinger · Florian Fitzal · Johann Lehrner · Daniel König • \\ Christine Deutschmann - Daphne Gschwantler-Kaulich
}

Received: 26 February 2020 / Accepted: 3 August 2020 / Published online: 3 September 2020

(C) The Author(s) 2020

\begin{abstract}
Summary
Background This study investigated the impact of curative breast cancer surgery on patient satisfaction concerning cosmetic results and quality of life (QoL). Methods In this study 61 participants completed questionnaires to evaluate their QoL and patient satisfaction with cosmetic results following breast cancer surgery. Cosmetic outcomes were evaluated by the breast surgeon and an independent breast specialist using the Harris scale and the breast analyzing tool (BAT).

Results Of the participants $71 \%$ completed all 4 followup visits, 38 (62\%) patients received breast-conserving therapy (BCT) and 23 (38\%) received a mastectomy. Surgery-associated complications arose in $2.6 \%$ of the patients who received BCT and $17.4 \%$ of patients who received a mastectomy. No significant differences in
\end{abstract}

C. Leser, MD, PhD ( $ه) \cdot$ Y. Y. Tan · C. Singer · R. Zeillinger •

C. Deutschmann · D. Gschwantler-Kaulich

Department of Obstetrics and Gynaecology,

Medical University of Vienna, Waehringer Guertel

18-20, 1090 Vienna, Austria

carmen.leser@meduniwien.ac.at

C. Leser, MD, PhD $\cdot$ Y. Y. Tan $\cdot$ C. Singer $\cdot$ R. Zeillinger

F. Fitzal · C. Deutschmann · D. Gschwantler-Kaulich

Comprehensive Cancer Center, Medical University of

Vienna, Vienna, Austria

F. Fitzal

Department of Surgery, Medical University of Vienna, Vienna, Austria

\section{J. Lehrner}

Department of Neurology, Medical University of Vienna,

Vienna, Austria

\section{König}

Clinical Division of Social Psychiatry, Department of Psychiatry and Psychotherapy, Medical University of Vienna, Vienna, Austria
QoL between BCT patients and mastectomy patients were observed immediately after surgery, or after 6 and 12 months. Breast asymmetry, measured using the BAT score, and QoL scores were worst immediately after surgery. The surgeon rated the cosmetic results as better compared to the independent breast expert $(p=0.001)$. Furthermore, patients aged over 60 years old were less satisfied with the cosmetic outcome compared to younger patients at the time of discharge $(p=0.024)$. Patients who received a mastectomy were less satisfied when the resected volume was higher.

Conclusion Patient satisfaction was lowest immediately after surgery but improved during the following months, despite continued breast asymmetry. For mastectomy patients, a lower resected volume led to a higher satisfaction with cosmetic results. Satisfaction is subjective and cannot be determined from the esthetic satisfaction of the surgeon or using an objective tool measuring breast asymmetry.

Keywords Breast cancer - Oncoplastic breast surgery · Quality of life · Breast analyzing tool · Cosmetic results

\section{Introduction}

The female breast plays an important role in society and in the lives of individual women. Besides its physiological role in breastfeeding, it is culturally associated with womanhood and fertility and represents a prominent secondary sex characteristic [1, 2]. Therefore, women who have undergone breast cancer surgery may suffer not only from the sequelae of surgery, but may also feel compromised with respect to their femininity $[3,4]$. A patient's satisfaction with the surgical outcome is influenced not only by socioeconomic factors, ethnicity, and medical knowledge, 
but also by the surgical technique used, side effects of radiotherapy, and size or shape-associated asymmetry [5].

Interestingly, a patient's satisfaction with the surgical outcome often differs considerably from the treating physician's perception [6]. While some women are satisfied with the cosmetic outcome, the treating physician is not; conversely, the physician might be satisfied with the esthetic result, considering possible surgical difficulties, while the patient might have expected a better outcome [6].

Considering the type of breast surgery there are remarkable differences in patient satisfaction. In 2003 Harcourt et al. [7] published a multicenter study reporting that breast reconstruction has a positive influence on anxiety, quality of life (QoL) and self-confidence; however, they reported no significant differences regarding the question of altered body image between patients after mastectomy with and without breast reconstruction, implying that breast reconstruction is not a universal panacea for the emotional and psychological consequences of a mastectomy.

Al-Ghazal et al. [6] reported significant differences in the outcomes concerning satisfaction and psychosocial morbidity (e.g. fear, depression, body image, sexuality and self-confidence) concerning different types of breast cancer surgery. Local wide excision was evaluated to be the best in terms of cosmetic outcomes and psychosocial aspects in their study, followed by breast reconstruction, while mastectomy without reconstruction was associated with lower levels of satisfaction. Accordingly, since skin and nipple-sparing mastectomies (SSM and NSM) have been proven to be oncologically safe, the number of immediate implant-based breast reconstructions has increased, with the best cosmetic outcomes and highest patient satisfaction reported for patients who underwent NSM with immediate reconstruction [8, 9].

We performed a prospective clinical trial investigating patient satisfaction with the cosmetic outcome, the QoL, differences in objective (breast analyzing tool, BAT) and subjective (patients, surgeons, independent breast specialist) evaluations of the cosmetic outcome, and changes in these parameters over time. We hypothesized that patient satisfaction with the cosmetic outcome and the QoL would increase over time, independent of the surgical technique performed.

\section{Materials and methods}

\section{Patients}

Between 2013 and 2014, 61 breast cancer patients were recruited for the study prior to planned surgical treatment for breast cancer. Of the patients 38 (62\%) underwent breast-conserving treatment (BCT), while 23 patients (38\%) underwent a mastectomy with or without implant-based breast reconstruction (IBBR). In the mastectomy group, 25\% underwent modified radical mastectomy (MRM) without breast reconstruction and 3\% underwent MRM with delayed IBBR. Lastly, 10\% underwent SSM/NSM with immediate IBBR. The $P$-values are purely explanatory and may be interpreted for generating new hypotheses only.

All procedures involving human participants were in accordance with the ethical standards of the institutional and/or national research committee, considering the 1964 Helsinki declaration and its later amendments or comparable ethical standards, and approval for this study was provided by the Institutional Review Board of the Ethics Commission, Medical University Vienna, approval number 073/2010. Informed consent was obtained from all individual participants included in the study.

\section{Data collection}

Data for this study were collected at four individual time points: at baseline (before surgery), on the day of discharge, and 6 and 12 months after surgery.

Clinical data, such as age, tumor type and stage, type of surgery, type of breast reconstruction, and occurrence of complications, were collected from the patients' medical records.

Digital photographs of the breasts were taken at each time interval. The photos were taken in front of a blue screen. All of them were frontal, including both shoulders and the mammillary fold, without the face. These photographs were then evaluated by the breast surgeon and by an independent breast surgeon using the Harris scale. Furthermore, the photographs were evaluated for breast symmetry using the BAT [10].

Questionnaires were used to assess patient satisfaction and QoL following BCT or mastectomy. A set of questions from the following validated questionnaires were compiled: EORTC (European Organisation for Research and Treatment of Cancer) QLQ (Quality of Life Questionnaire) C30, EORTC QLQ-BR23 (breast cancer module) [11], FBK R-23 [12], and one question from the Ludwigs-Maximillian University Munich. The questionnaire was then used to evaluate patients' level of satisfaction with the cosmetic result [13]. These questionnaires were used because of the symptom scales (arm symptoms, breast symptoms, and pain) in the EORTC and because the FBK R-23 includes items addressing anxiety, psychosomatic disorders, deficit of information, limitations in daily life, and social pressure. The question from the Munich instrument determines patients' satisfaction with the cosmetic result. 
original article

Table 1 Patients characteristics

\begin{tabular}{|c|c|c|c|c|}
\hline & $\begin{array}{l}\text { BCT } \\
n=38(62 \%)\end{array}$ & $\begin{array}{l}\text { MRM } \\
n=17(28 \%)\end{array}$ & $\begin{array}{l}\text { SSM } \\
n=3(5 \%)\end{array}$ & $\begin{array}{l}\text { NSM } \\
n=3(5 \%)\end{array}$ \\
\hline Median age (years; range) & $57 ; 37-76$ & $64 ; 39-85$ & $55 ; 52-58$ & $45 ; 40-52$ \\
\hline \multicolumn{5}{|l|}{ Tumor status } \\
\hline pTis & 8 & 2 & 0 & 0 \\
\hline pT1a & 2 & 1 & 0 & 0 \\
\hline pT1b & 8 & 3 & 1 & 1 \\
\hline pT1c & 14 & 2 & 1 & 2 \\
\hline pT2 & 6 & 5 & 0 & 0 \\
\hline pT3 & 0 & 3 & 1 & 0 \\
\hline pT4 & 0 & 1 & 0 & 0 \\
\hline \multicolumn{5}{|l|}{ Nodal status } \\
\hline pNO & 26 & 9 & 2 & 3 \\
\hline pN1 & 3 & 2 & 0 & 0 \\
\hline pN2 & 0 & 1 & 1 & 0 \\
\hline pN3 & 1 & 2 & 0 & 0 \\
\hline NA & 8 & 3 & 0 & 0 \\
\hline \multicolumn{5}{|l|}{ Histology } \\
\hline DCIS & 8 & 2 & 0 & 0 \\
\hline IDC & 11 & 5 & 0 & 2 \\
\hline ILC & 6 & 0 & 0 & 0 \\
\hline $\mathrm{IDC}+\mathrm{DCIS}$ & 13 & 6 & 3 & 1 \\
\hline $\mathrm{ILC}+\mathrm{DCIS}$ & 0 & 4 & 0 & 0 \\
\hline \multicolumn{5}{|l|}{ Reconstruction } \\
\hline IBBR & 0 & 0 & 3 & 3 \\
\hline Flap reconstruction & 0 & 0 & 0 & 0 \\
\hline
\end{tabular}

\section{Evaluating the cosmetic outcome}

\section{Harris scale}

The Harris Scale, a 4-point Likert scale, was used by the surgeon who performed the operation and an independent breast surgeon to evaluate the cosmetic outcome of the treated versus untreated breast after breast cancer surgery [14]. We used the Harris scale because it is a simple and well-established scale with proven utility.

\section{Breast analyzing tool (BAT)}

The BAT software system calculates a breast symmetry index using digital photographs. The index is calculated by determining the difference in size and shape between breasts (frontal and side view). If the operated breast does not differ in shape and size from the contralateral side, the breasts are considered to be in perfect symmetry. Further information regarding this tool is available in previous literature [10]. We excluded patients who had undergone a total unilateral mastectomy.

\section{Statistical analysis}

We compared the QoL and cosmetic outcome of patients who received BCT or mastectomy, with or with- out reconstruction, at four time points $(\mathrm{T} 0=$ prior to surgery, $\mathrm{T} 1=$ at hospital discharge, $\mathrm{T} 2=6$ months after surgery, and T3= 12 months after surgery).

Scores are presented as percent, mean, or median and standard deviation (SD). Wilcoxon signed-rank tests were used to compare the differences between groups and variables at the four time points. A $p$ value $<0.05$ was considered as statistically significant. All data analyses were conducted using SPSS software (version 21 for Windows, SPSS, Chicago, IL, USA).

\section{Results}

\section{Patients and follow-up}

Of the 61 patients, 57 (93\%) completed a baseline (presurgery) questionnaire (T0) and 56 patients (92\%) completed the questionnaire on the day of discharge (T1). At the 6-month follow-up postsurgery (T2), 45 patients $(74 \%)$ completed the questionnaire and at 12 months post-surgery (T3), 43 patients participated (71\%). The total patient drop-out was $29 \%$.

Patients' characteristics are shown in Table 1. The median age was 59 years (range 37-85 years), 38 patients $(62 \%)$ underwent breast-conserving surgery and 23 patients $(38 \%)$ underwent mastectomy. In the mas- 
Table 2 Mean and standard deviation of the quality of life at different time points

\begin{tabular}{|c|c|c|c|c|c|}
\hline & & Baseline (T0) & Day of discharge (T1) & $\begin{array}{l}\text { Postsurgery, } 6 \text { months } \\
\text { (T2) }\end{array}$ & $\begin{array}{l}\text { Postsurgery, } 12 \text { months } \\
\text { (T3) }\end{array}$ \\
\hline Total participants & - & $57 / 61(93 \%)$ & $55 / 61(90 \%)$ & $44 / 61(72 \%)$ & $42 / 61(69 \%)$ \\
\hline $\begin{array}{l}\text { EORTC } \\
\text { QLQ C } 30\end{array}$ & - & Mean score, \% (SD) & Mean score, \% (SD) & Mean score, \% (SD) & Mean score, \% (SD) \\
\hline Global health status/QoL & Overall QoL & $67(23)$ & $55(22)$ & $72(21)$ & $87(17)$ \\
\hline \multirow[t]{5}{*}{ Functional scales } & Physical functioning & $91(17)$ & $68(23)$ & $84(18)$ & $95(9)$ \\
\hline & Role functioning & $91(19)$ & $56(36)$ & $73(27)$ & $90(18)$ \\
\hline & Emotional functioning & $62(23)$ & $61(27)$ & $67(23)$ & $79(21)$ \\
\hline & Cognitive functioning & 87 (18) & $84(23)$ & $90(18)$ & $96(9)$ \\
\hline & Social functioning & $87(20)$ & $69(34)$ & $75(32)$ & $83(30)$ \\
\hline \multirow[t]{9}{*}{ Symptom scales/items } & Fatigue & $18(26)$ & $38(28)$ & $29(26)$ & $10(17)$ \\
\hline & Nausea and vomiting & $2(7)$ & $12(22)$ & $8(17)$ & $2(6)$ \\
\hline & Pain & $13(21)$ & $43(29)$ & $24(23)$ & $5(13)$ \\
\hline & Dyspnea & $15(28)$ & $21(29)$ & $8(16)$ & $4(13)$ \\
\hline & Insomnia & $28(32)$ & $41(34)$ & $24(29)$ & $14(22)$ \\
\hline & Appetite loss & $10(21)$ & $20(30)$ & $11(23)$ & $4(11)$ \\
\hline & Constipation & $7(24)$ & $19(33)$ & $8(19)$ & $2(9)$ \\
\hline & Diarrhea & $14(24)$ & $9(21)$ & $5(15)$ & $1(5)$ \\
\hline & Financial difficulties & $7(17)$ & $7(21)$ & $7(20)$ & $6(18)$ \\
\hline \multirow[t]{4}{*}{ Functional scales } & Body image & $92(14)$ & $77(29)$ & $78(29)$ & $86(22)$ \\
\hline & Sexual functioning & $31(33)$ & $17(32)$ & $29(32)$ & $41(37)$ \\
\hline & Sexual enjoyment & $81(26)$ & $74(23)$ & $79(21)$ & $75(33)$ \\
\hline & Future perspective & $35(38)$ & $34(35)$ & $51(30)$ & $60(31)$ \\
\hline \multirow[t]{4}{*}{ Symptom scales/items } & $\begin{array}{l}\text { Systemic therapy side } \\
\text { effects }\end{array}$ & $15(17)$ & $20(17)$ & $14(15)$ & $7(12)$ \\
\hline & Breast symptoms & $13(17)$ & $37(28)$ & $22(21)$ & $10(14)$ \\
\hline & Arm symptoms & $5(13)$ & $32(26)$ & $16(17)$ & $4(8)$ \\
\hline & Upset by hair loss & $44(29)$ & $47(42)$ & $46(40)$ & $33(27)$ \\
\hline $\begin{array}{l}\text { Patient satisfaction } \\
\text { scale }\end{array}$ & Cosmetic results & $\mathrm{N} / \mathrm{A}$ & $66(38)$ & $57(43)$ & $59(41)$ \\
\hline FBK R 23 & Baseline (TO) & $\begin{array}{l}\text { Day of discharge } \\
\text { (T1) }\end{array}$ & $\begin{array}{l}\text { Postsurgery, } 6 \text { months } \\
\text { (T2) }\end{array}$ & \multicolumn{2}{|c|}{ Postsurgery, 12 months (T3) } \\
\hline- & Mean score, \% (SD) & Mean score, \% (SD) & Mean score, \% (SD) & \multicolumn{2}{|l|}{ Mean score, \% (SD) } \\
\hline $\begin{array}{l}\text { Psychosomatic com- } \\
\text { plaints }\end{array}$ & $35(22)$ & $37(26)$ & $28(21)$ & \multicolumn{2}{|l|}{$18(19)$} \\
\hline Fear & $40(24)$ & $51(26)$ & $37(24)$ & \multicolumn{2}{|l|}{$21(21)$} \\
\hline Information deficits & $47(34)$ & $42(37)$ & $27(18)$ & \multicolumn{2}{|l|}{$17(20)$} \\
\hline Everyday life restrictions & $34(27)$ & $45(26)$ & $36(26)$ & \multicolumn{2}{|l|}{$19(23)$} \\
\hline Social strains & $25(10)$ & $13(5)$ & $20(16)$ & \multicolumn{2}{|l|}{$4(7)$} \\
\hline Total stress score & $32(10)$ & $46(21)$ & $45(19)$ & \multicolumn{2}{|l|}{21 (22) } \\
\hline
\end{tabular}

tectomy group, 17 patients (28\%) underwent MRM, while 6 patients $(10 \%)$ underwent SSM/NSM (3 patients SSM; 3 patients NSM) with immediate IBBR and 2 patients $(3 \%)$ underwent delayed IBBR after MRM, while 15 patients $(25 \%)$ had no breast reconstruction.

Of the patients 11 (18\%) with small tumors (pT1) received mastectomy owing to disease recurrence or a BRCA mutation status. Surgery-associated complications were observed in five patients $(8 \%)$; one hematoma in the BCT group, one hematoma and one seroma in the mastectomy group and two pa- tients after SSM/NSM with immediate IBBR lost the implants.

\section{Patient QoL}

The percentages given show the questionnaire scores for each symptom or an overall score for the QoL. No significant differences were found between the first and the last visit for arm symptoms (BCT: $p=0.500$; ME: $p=0.892$ ), breast symptoms (BCT: $p=0.864$; ME: $p=0.726$ ), and pain (BCT: $p=0.310$; ME: $p=0.418$ ). These parameters were highest at the time of hospital 

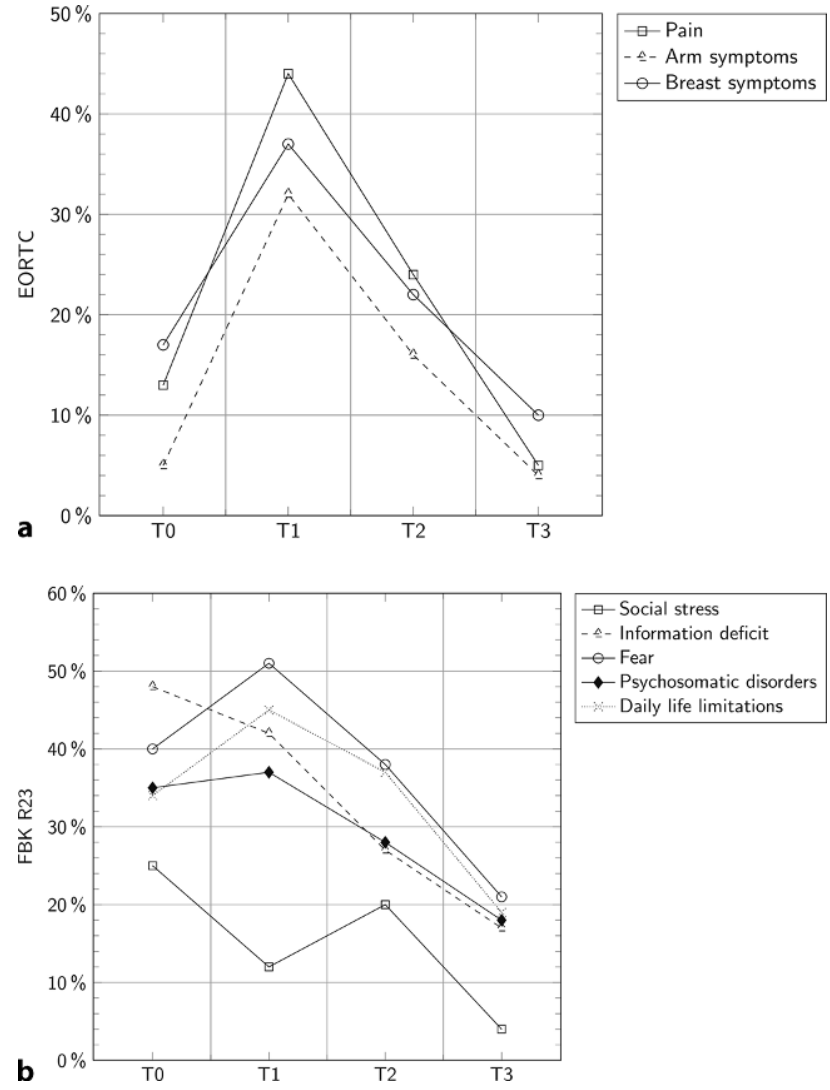

Fig. 1 a Patient quality of life over time (EORTC), b patient quality of life over time (FBK R 23) shown as mean \%. Within the EORTC the large number of symptoms after the surgery can be seen, which become lowering over time and were lowest 12 months after. In the FBK R 23 also all limitations were best 12 months after surgery

discharge. Patients' median QoL was 50\% at the time of hospital discharge, the date with the lowest QoL compared to the other time-points $(p=0.001)$, with values of $67 \%$ for BCT and $33 \%$ for ME. The highest QoL for patients who received BCT was 1 year after surgery, compared to baseline before surgery (BCT: $p=0.001$, ME: $p=0.100$ ). For mean and SD see Table 2 . When we investigated if the type of breast surgery had any influence on patients' QoL, we did not find any statistically significant differences. The information deficit was highest initially (48\%) and decreased over time (T3: 17\%). At the time of discharge, major issues were fear (51\%) and daily life limitations (45\%), but these issues also decreased to lower values than at the beginning (fear T3: 21\%, information deficit T3: 19\%). Fear was significantly lower at T3 than at T0 $(p=0.014$; Fig. 1).

\section{Cosmetic results}

We took only frontal pictures of the breasts, consistent with the requirements of the BAT, which were used to measure breast symmetry.
Table 3 Frequency table of the Harris scale for surgeons and the specialist

\begin{tabular}{|l|l|l|l|l|l|} 
& Excellent & Good & Fair & Poor & Missing data \\
\hline Surgeon & 34 & 10 & 8 & 4 & 3 \\
\hline Specialist & 10 & 23 & 17 & 9 & 0 \\
\hline
\end{tabular}

The mean satisfaction of the surgeon with the cosmetic result was high (mean of $83 \%$ on the Harris scale, $90 \%$ for BCT, and $70 \%$ for ME). The satisfaction of the specialist who was not involved in the surgery of the individual patient was lower (mean of $64 \%$ on the Harris scale, $74 \%$ for BCT, and $48 \%$ for ME; $p=0.001$ ). A frequency table of the Harris scale from the surgeons and the specialist is shown in Table 3. The satisfaction of the patients was very different between those who received BCT (mean $86 \%$ ) and $\mathrm{ME}$ (mean 37\%). The BAT score requires a nipple and therefore it was not possible for ME. The mean for BCT was $72 \%$ (Fig. 2).

The BAT score was lowest (24\%) prior to surgery, indicating that the breasts were the most symmetrical at this time point. Breast asymmetry was highest on the day of discharge. This difference was statistically significant ( $p=0.049$ ). Over time, the BAT score improved and almost returned to the baseline score at 12 months postsurgery, as did the satisfaction of patients who underwent BCT $(p=0.049)$.

At the time of hospital discharge (T1) 57\% (BCT: $62 \%$, ME: $47 \%$ ) of all patients were generally satisfied with the cosmetic result, while $18 \%$ (BCT: $11 \%$, ME: $31 \%$ ) of patients were dissatisfied; the remainder did not answer this question. Six months after surgery (T2) 58\% (BCT: $79 \%$, ME: $19 \%$ ) of all patients were satisfied and 38\% (BCT: $14 \%$, ME: $81 \%$ ) were dissatisfied with the cosmetic result and 12 months after surgery (T3) 58\% (BCT: 85\%, ME: 13\%) were satisfied, while $28 \%$ (BCT: $7 \%$, ME: $63 \%$ ) were dissatisfied. The mean age of patients who were "not at all" or "only a little" happy with the cosmetic result was 64 years (BCT: 65 years, ME: 58 years). Those who were "quite a bit" or "very much" happy were on average 58 years old (BCT: 57 years, ME: 65 years). Of the patients 41 (67\%) were under 65 years old. We found no significant difference in stage, tumor type, or method of operation. Patients were especially dissatisfied with the cosmetic outcome on the day of discharge compared to baseline $(p=0.024)$. Furthermore, satisfaction with the cosmetic result significantly decreased after discharge in patients younger than 65 years who underwent mastectomy ( $p=0.049)$, but not in patients over 65 years who underwent mastectomy (Fig. 3).

Fig. 4 shows examples of a poor cosmetic outcome (case 21; BAT score 6.5), a median example on the basis of the BAT score (case 4; BAT score: 4), and a good cosmetic outcome (case 7; BAT score: 2). The surgeon and the specialist evaluated cases 7 and 4 as an excellent cosmetic outcome (Harris scale: 4 ), while case 21 was evaluated as poor (Harris scale: 2). 


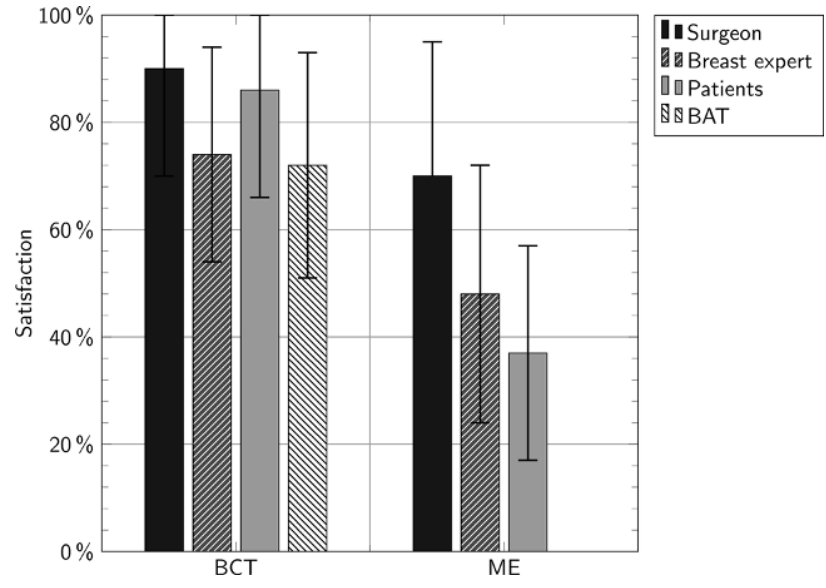

Fig. 2 Satisfaction with the cosmetic result (mean values and $\mathrm{SD}$ ). The difference of the satisfaction with the cosmetic result within BCT and ME is shown. Surgeons were more satisfied with the cosmetic result than patients and the breast specialist. Patients with ME are not as satisfied as patients with BAT

In mastectomy patients, the satisfaction of the cosmetic result was higher when the resected volume was lower $(p=0.023)$ We did not find the same phenomenon in patients who received BCT $(p=0.065)$. The resected volume of a mastectomy was linear to the cup size of the patients.

\section{Discussion}

Our study investigated the impact of breast surgery on patients' QoL and found a significant improvement in patients' QoL and cosmetic outcome over time. This is consistent with previous findings showing that most long-term survivors of breast cancer ultimately reach QoL levels comparable to healthy controls $[15,16]$.

The improvement in the overall QoL over time may indicate that patients had more time to come to terms with the severe diagnosis of breast cancer. Most of the study participants completed the treatment by their third or fourth visit. This was reflected in the observed increase in emotional functioning, which has also been reported previously [7, 17]. We found a significant decrease in daily life limitations 12 months after surgery. We suggest that this is because of the anxiety and frequent examinations before the operation, so that the patients felt limited in their social life.

Our study also showed that older patients are less satisfied with the cosmetic outcome than younger women immediately after surgery, but not as time progresses. The groups also did not differ in stage, tumor type, or method of operation. The lower satisfaction might be due to age-based self-perception differences or other reasons, which would require more exploration in future studies, because of the small sample size.

Breast asymmetry improved over time and almost returned to the baseline scores 1 year after surgery.

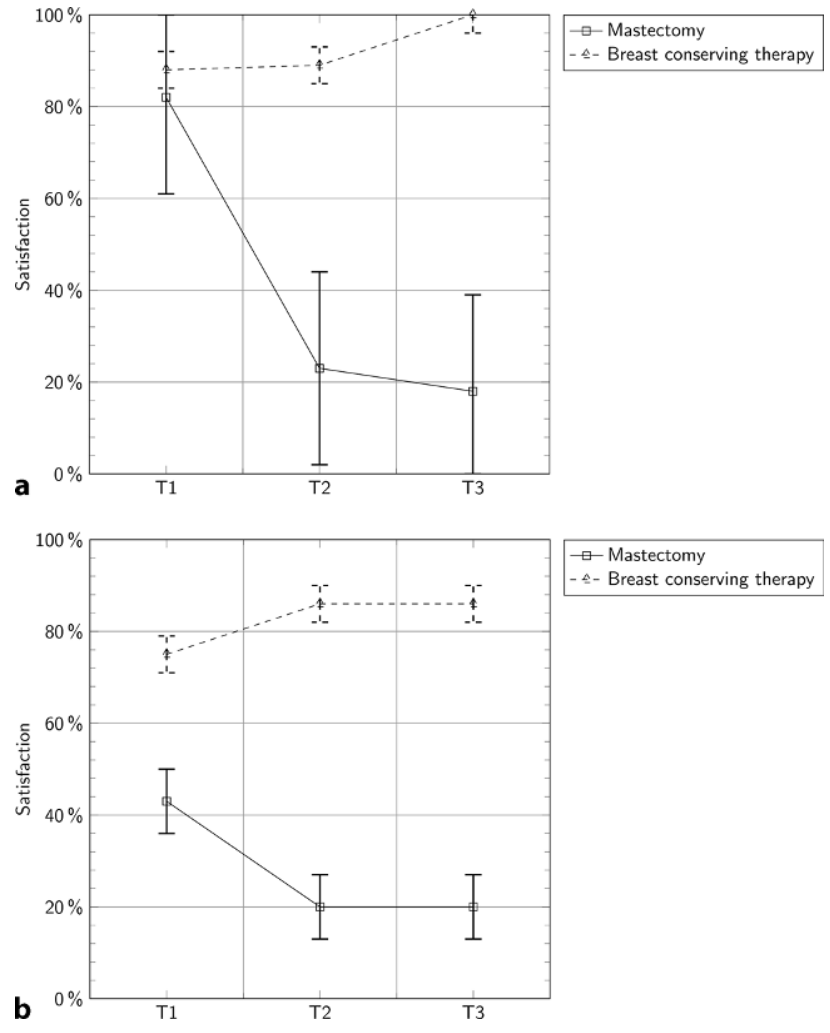

Fig. 3 a Patients $<65$ years who were satisfied or very satisfied with surgery outcome; $\boldsymbol{b}$ Patients $>65$ years who were satisfied or very satisfied with surgery outcome shown as mean $\%$ and SD. Patients with BAT become more satisfied with the cosmetic result over time, but a difference between ages can be seen

As shown in our previous study, breast symmetry has no significant impact on QoL in breast cancer survivors [18], which has since been validated in a larger study [19]. Furthermore, we did not find any association between the type of breast surgery and patients' QoL or their satisfaction with the cosmetic result. This could be because patients who receive BCT in our department automatically receive oncoplastic surgery to reconstruct the defect. In most cases, this is a simple glandular rotation. Between patients undergoing ME with or without reconstruction, we did not find any differences in QoL and satisfaction with the cosmetic outcome. The small study population, especially in the reconstructed group, could be the reason.

Our study was limited by the decrease in patient participation over time (from $93 \%$ to $71 \%$ ). This is not uncommon and is similar to other studies [20]. It could have been because of a bias that unsatisfied patients changed the institution. Since our institution is a large hospital, many patients come for surgical treatment and change to a smaller, local hospital for further treatment. Higher participation was observed in our study at the two initial time intervals, likely because patients were admitted for the scheduled surgery and were still hospitalized after the procedure. At the later time points, a decline in partici- 
Fig. 4 Examples of good and poor cosmetic outcome. Case 7: invasive ductal carcinoma, pT1b, breast conserving therapy, BAT score 2, specialist and surgeon evaluated as excellent outcome Harris scale 4. Case 4: invasive ductal carcinoma, pT1c, breast conserving therapy, BAT score 4, specialist and surgeon evaluated as excellent outcome Harris scale 4. Case 21: invasive ductal carcinoma, $\mathrm{pT} 1 \mathrm{~b}$, breast conserving therapy, BAT score 6.5, specialist and surgeon evauated as poor outcome Harris scale 2
Case 7
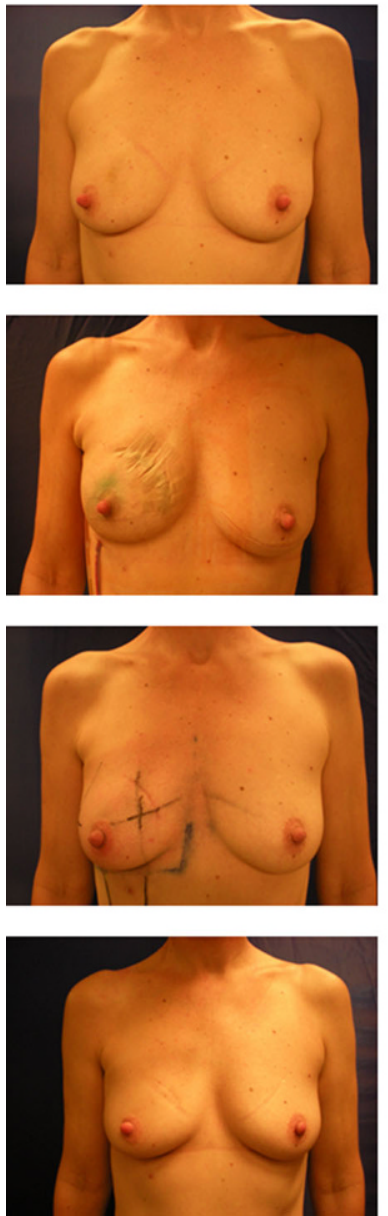

Case 4
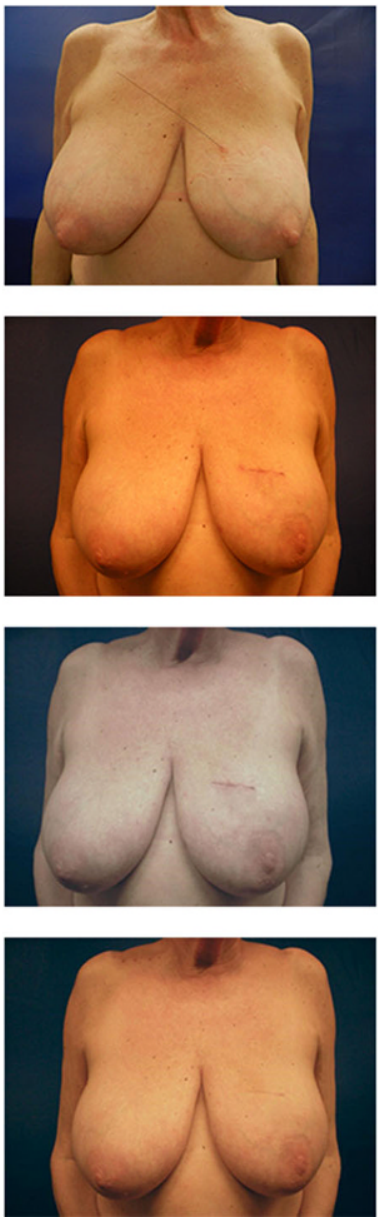

Case 21

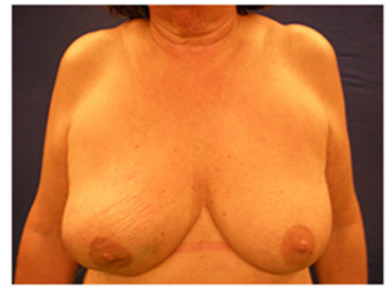

to

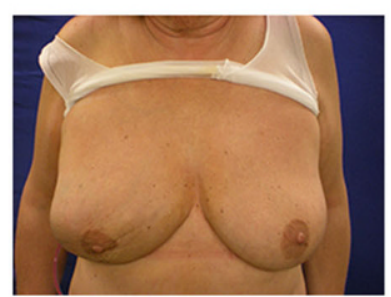

t1
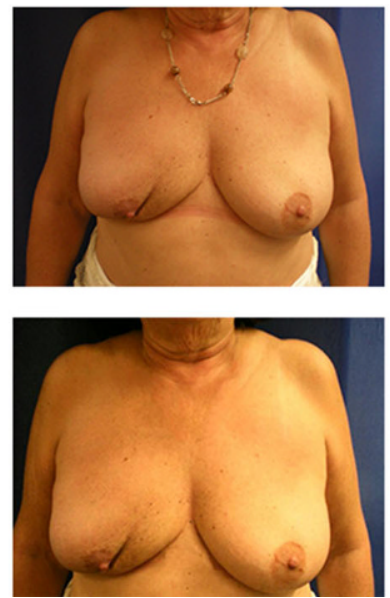

pation could be due to diminishing motivation or interest as well as difficulty in transportation, especially for older patients. We only took frontal pictures of the breasts since this approach was standardized and easy to perform. In future studies, pictures should ideally be taken from multiple different standardized planes. Lastly, the study is also limited because of the small sample size and the variety of operation types, which reduced the size of the subgroups. An endpoint was difficult to define because all scores were subjective, although we improved objectivity by using the BAT.

In conclusion, our study shows that the QoL of breast cancer patients is significantly affected by surgical treatment, but only immediately after breast surgery. Older patients were less satisfied with the cosmetic result directly after surgery, which emphasizes the importance of integrating possible postsurgery cosmetic outcomes into the preoperative information for older patients, to the same extent as for younger patients.

Lower resected volume is associated with higher satisfaction of patients in mastectomy. Perhaps this phenomenon could be seen because of the lower body mass index (BMI) of these patients and the associated lower number of side effects [21].

Acknowledgements We thank Ella Asseryanis, MD, Ass-Prof; Leo Auerbach, MD, Ass-Prof; Andreas Berger, MD, Ass-Prof; Heinz Kölbl, MD, Prof; Julian Marschalek, MD; Ljubomir Petricevic, MD, Priv-Doz, Ass-Prof; Georg Pfeiler, MD, Priv.-Doz., Ass-Prof; Michael Seifert, MD, Prof; and Muy-Kheng Tea, MD, Priv.-Doz., Ass-Prof for their crucial input for evaluating the cosmetic results of the patients upon whom they operated.

Funding This study did not receive any financial support.

Funding Open access funding provided by Medical University of Vienna.

\section{Compliance with ethical guidelines}

Conflict of interest C. Leser, Y.Y. Tan, C. Singer, R. Zeillinger, F. Fitzal, J. Lehrner, D. König, C. Deutschmann, and D. Gschwantler-Kaulich declare that they have no competing interests.

Ethical standards Informed consent was obtained from all individual participants included in the study. The study protocol has been approved by the research institute's committee on human research (Ethics commission Medical University Vienna, approval number 073/2010). Additional written in- 
formed consent was obtained from all individual participants or their legal representatives for whom identifying information is included in this article.

Open Access This article is licensed under a Creative Commons Attribution 4.0 International License, which permits use, sharing, adaptation, distribution and reproduction in any medium or format, as long as you give appropriate credit to the original author(s) and the source, provide a link to the Creative Commons licence, and indicate if changes were made. The images or other third party material in this article are included in the article's Creative Commons licence, unless indicated otherwise in a credit line to the material. If material is not included in the article's Creative Commons licence and your intended use is not permitted by statutory regulation or exceeds the permitted use, you will need to obtain permission directly from the copyright holder. To view a copy of this licence, visit http://creativecommons.org/licenses/by/4.0/.

\section{References}

1. Didie ER, Sarwer DB. Factors that influence the decision to undergo cosmetic breast augmentation surgery. JWomens Health. 2003;12:241-53.

2. Sarwer DB, Magee L, Clark V. Physical appearance and cosmetic medical treatments: physiological and sociocultural influences. J Cosmet Dermatol. 2003;2:29-39.

3. Glanz K, Lerman C. Psychosocial impact of breast cancer: a critical review. Ann Behav Med. 1992;14:204-12.

4. Yurek D, Farrar W, Andersen BL. Breast cancer surgery: Comparing surgical groups and determining individual differences in postoperative sexuality and body change stress. JConsult Clin Psychol. 2000;68:697.

5. Ashing-Giwa KT, Padilla G, Tejero J, Kraemer J, Wright K, Coscarelli A, et al. Understanding the breast cancer experience of women: a qualitative study of African American, Asian American, Latina and Caucasian cancer survivors. Psychooncology. 2004;13:408-28.

6. Al-Ghazal S, Fallowfield L, Blamey R. Comparison of psychological aspects and patient satisfaction following breast conserving surgery, simple mastectomy and breast reconstruction. Eur JCancer. 2000;36:1938-43.

7. Harcourt DM, Rumsey NJ, Ambler NR, Cawthorn SJ, Reid CD, Maddox PR, et al. The psychological effect of mastectomy with or without breast reconstruction: a prospective, multicenter study. Plast Reconstr Surg. 2003;111:1060-8.

8. Zhang H, Li Y, Moran MS, Haffty BG, Yang Q. Predictive factors of nipple involvement in breast cancer: a systematic review and meta-analysis. Breast Cancer Res Treat. 2015;151:239-49.

9. Munhoz AM, Montag E, Filassi JR, Gemperli R. Immediate nipple-areola-sparing mastectomy reconstruction: an up- date on oncological and reconstruction techniques. World J Clin Oncol. 2014;5:478-94.

10. Fitzal F, Krois W, Trischler H, Wutzel L, Riedl O, Kühbelböck U, et al. The use of a breast symmetry index for objective evaluation of breast cosmesis. Breast. 2007;16:429-35.

11. Herschbach P, Marten-Mittag B, Henrich G. Revision und psychometrische Prüfung des Fragebogen zur Belastung von Krebskranken (FBK-R23). Z Med Psychol. 2003;12:69-76.

12. Fayers P, BottomleyAO, Group EQoL. Quality oflife research within the EORTC - the EORTC QLQ-C30. Eur J Cancer. 2002;38:125-33.

13. Härtl K, Janni W, Kästner R, Sommer H, Strobl B, RackB, etal. Impact of medical and demographic factors on long-term quality of life and body image of breast cancer patients. Ann Oncol. 2003;14:1064-71.

14. Cassileth L, Kohanzadeh S, Amersi F. One-stage immediate breast reconstruction with implants: a new option for immediate reconstruction. Ann Plast Surg. 2012;69:134-8.

15. Ganz PA, Rowland JH, Desmond K, Meyerowitz BE, Wyatt GE. Life after breast cancer: understanding women's health-related quality of life and sexual functioning. J Clin Oncol. 1998;16:501-14.

16. Shimozuma K, Ganz PA, Petersen L, Hirji K. Quality of life in the first year after breast cancer surgery: rehabilitation needs and patterns of recovery. Breast Cancer Res Treat. 1999;56:45-57.

17. Henderson VP, Clemow L, Massion AO, HurleyTG, Druker S, Hébert JR. The effects of mindfulness-based stress reduction on psychosocial outcomes and quality of life in earlystage breast cancer patients: a randomized trial. Breast Cancer Res Treat. 2012;131:99-109.

18. Exner R, Krois W, Mittlbock M, Dubsky P, Jakesz R, Gnant M, et al. Objectively measured breast symmetry has no influence on quality of life in breast cancer patients. Eur J Surg Oncol. 2012;38:130-6.

19. Kim MK, Kim T, Moon HG, Jin US, Kim K, Kim J, et al. Effect of cosmetic outcome on quality of life after breast cancer surgery. Eur J Surg Oncol. 2015;41:426-32.

20. Kissane DW, Grabsch B, Clarke DM, Smith GC, Love AW, Bloch S, et al. Supportive-expressive group therapy for women with metastatic breast cancer: Survival and psychosocial outcome from a randomized controlled trial. Psychooncology. 2007;16:277-86.

21. Burkheimer E, Starks L, Khan M, Oostendorp L, Melnik MK, Chung $\mathrm{MH}$, et al. The impact of obesity on treatment choices and outcomes in operable breast cancer. Am J Surg. 2019;217(3):474-7.

Publisher's Note Springer Nature remains neutral with regard to jurisdictional claims in published maps and institutional affiliations. 